\title{
A ATUALIDADE DA PRODUÇÃO CIENTÍFICA SOBRE A GINÁSTICA ESCOLAR NO BRASIL
}

\author{
Núbia dos Santos Lisboa, Universidade Federal do Recôncavo da Bahia-UFRB, \\ Recôncavo da Bahia, Bahia - Brasil \\ David Romão Teixeira, Universidade Federal do Recôncavo da Bahia-UFRB, \\ Recôncavo da Bahia, Bahia - Brasil
}

\section{RESUMO}

Este artigo trata da investigação de iniciação científica voluntária intitulada "A teoria geral da ginástica escolar - análise da produção científica brasileira". Tendo como objetivo elaborar um balanço da produção científica presentes nas Revistas (Motrivivência, Movimento, Revista Brasileira de Ciências do Esporte (RBCE), Motriz, Pensar a Prática), e nas teses e dissertações presentes no banco de teses da CAPES. Para atingir os objetivos utilizamos métodos próprios da pesquisa social, alicerçado na base teórica do materialismo histórico dialético. Na investigação utilizamos procedimentos metodológicos da pesquisa bibliográfica como: análise documental e revisão bibliográfica sobre a temática. Como ferramentas científicas, utilizamos o computador e as fichas de síntese. São resultados desta etapa da pesquisa: a) 51 artigos encontrados nas revistas tratam das problemáticas da ginástica, 11 de ginástica escolar, sendo este o terceiro tema mais discutido, atrás da ginástica esportiva e em academia; b) nas teses e dissertações foram encontrados 166 trabalhos, sendo 152 Mestrado e 14 Doutorado, apenas 9 abordam a ginástica escolar. Com uma análise ainda inicial, é possível indicar que a produção sobre ginástica escolar nas fontes pesquisadas é muito reduzida, principalmente nas teses e dissertações.

Palavras-Chave: Ginástica escolar; Educação Física; Produção científica.

\section{THE PRESENT OF SCIENTIFIC PRODUCTION ON THE SCHOOL GYM IN BRAZIL}

\begin{abstract}
This article is about the research of scientific initiation voluntary entitled "The general theory of gymnastics school - analysis of the Brazilian scientific production". Having aimed to draw up a balance sheet of the scientific production present in magazines (Motrivivência, Movimento, Revista Brasileira de Ciências do Esporte (RBCE), Motriz, Pensar a Prática), and in the theses and dissertations present in CAPES thesis. To achieve the goals we use own methods of social research, based on theoretical basis of historical materialism dialectical. In research we use methodological procedures of bibliographic research as: documentary analysis and review of the literature on the topic. As scientific tools, we use the computer and the summary sheets. Are the results of this stage of the research: a) 51 articles found in the magazines deal with the problems of gymnastics, 11 Conexões: revista da Faculdade de Educação Física da UNICAMP, Campinas, v. 10, n. Especial, p. 1-9, dez. 2012. ISSN: 1983-9030
\end{abstract}


gymnastics school, and this is the third most discussed topic, behind the gym sports and in academia; (b) in the theses and dissertations were found 166 jobs, 152 Masters and 14 Doctoral, only 9 address the gymnastics school. With an analysis yet initial, and possible to indicate that the production on gymnastics school in the sources searched is very small, mainly in the theses and dissertations.

Key-Words: Gymnastics school; Physical Education; Scientific production.

\section{LA ACTUALIDAD DE LA PRODUCCIÓN CIENTÍFICA EN EL GIMNASIA ESCOLAR EN BRASIL}

\section{RESUMÉN}

Este artículo es sobre la investigación de iniciación científica voluntario titulado "La teoría general de la gimnasia escuela - análisis de la producción científica brasileña". Con objeto de hacer un balance de la producción científica presente en revistas (Motrivivência, Movimento, Revista Brasileira de Ciências do Esporte (RBCE), Motriz, Pensar a Prática), y en la presente tesis y disertaciones en cabos tesis. Para lograr los objetivos que utilizamos métodos propios de la investigación social, sobre la base de base teórica del materialismo histórico dialéctico. En la investigación utilizamos procedimientos metodológicos de investigación bibliográfica como: análisis documental y revisión de la literatura sobre el tema. Como instrumentos científicos, que utilice el ordenador y las hojas de resumen. Son los resultados de esta etapa de la investigación: A) 51 artículos en revistas especializadas con los problemas de la gimnasia, gimnasia 11 escuela, y este es el tercer tema más discutido, detrás del gimnasio y de la academia; (b) en las tesis y disertaciones se encontraron 166 puestos de trabajo, 152 maestros y 14 doctores, sólo 9 dirección la gimnasia escolar. Con un análisis aún inicial, y posible indicar que la producción de gimnasia escolar en las fuentes buscan es muy reducido, sobre todo en las tesis y disertaciones.

Palabras-Clave: La gimnasia escuela; Educación Física; Producción científica. 


\section{INTRODUÇÃO}

Este trabalho trata das atividades desenvolvidas na investigação de iniciação científica voluntária intitulada "A teoria geral da ginástica escolar - análise da produção científica brasileira". Está investigação está articulada com a pesquisa matricial "Ginásticas Alegria na Escola: realidade e possibilidades na cidade de Amargosa", que envolve atividades de ensino-pesquisa-extensão, coordenada e orientada pelo Prof. Msc. David Romão Teixeira, e organizada pelo grupo GEPEFE - Educação, Formação de Professores e Educação Física - da Universidade Federal do Recôncavo da Bahia.

A ginástica é um dos elementos do que chamamos de cultura corporal, ela é uma das primeiras formas sistematizadas das práticas corporais, inclusive por muito tempo, sendo tratada e confundida com o que hoje chamamos de Educação Física, por isso a história da ginástica ser a origem da própria Educação Física, seja ela nos seu sentido genérico, ou como disciplina escolar. ${ }^{1}$ No contexto escolar brasileiro a ginástica se faz presente desde seus primórdios, como a disciplina responsável pela educação corporal da juventude, durante esse percurso o trato com o conhecimento da ginástica nas escolas brasileiras passou por diversas modificações, seus objetivos, seus métodos, sua importância e presença no sistema formal de ensino foram alterados sempre de acordo com os interesses da organização social do país, chegando hoje a ser um conhecimento em via de extinção nas escolas.

Entendemos a ginástica como um bem cultural, criado e desenvolvido a partir de necessidades humanas, historicamente acumulada e sistematizada, sob condições sociais contraditórias, tornando-se um legado a ser ensinado e praticado por todos interessados, como todas as demais conquistas da humanidade, superando as barreiras da divisão de classes sociais e da propriedade privada, pilares da sociedade capitalista, sendo assim, um conhecimento que deve ser garantido a todos. ${ }^{2}$

A escola pública toma o centro de nossas discussões principalmente por ser o espaço privilegiado do sistema educacional do país, sendo sua obrigação apresentar e desenvolver os conhecimentos historicamente acumulados às novas gerações, sendo no caso brasileiro, Conexões: revista da Faculdade de Educação Física da UNICAMP, Campinas, v. 10, n. Especial, p. 1-9, dez. 2012.3 ISSN: 1983-9030 
muitas vezes a única oportunidade de milhares de pessoas acessarem o conhecimento científico de forma gratuita e sistematizada. ${ }^{3}$ Fazemos esse destaque porque, reconhecemos o papel oficial da instituição escolar na sociedade capitalista, sua importância na manutenção do status quo vigente, e no amortecimento dos confrontos entre as classes sociais distintas, ${ }^{4}$ retardando muitas vezes a ampliação do padrão do nível cultural dos trabalhadores.

Sendo assim, o desaparecimento e o precário desenvolvimento da ginástica no contexto escolar, representam a negação deste conhecimento aos trabalhadores, privando-os de usufruírem o resultado do próprio trabalho, tônica atual da organização social vigente, por isso, quando tratamos da socialização dos conhecimentos ginásticos, relacionamos diretamente com a luta pela socialização dos meios de produção e da riqueza, pois, sem isto estaríamos presos às ilusões idealistas.

\section{OBJETIVOS}

Dentro desta tarefa investigativa é que este artigo tem como objetivo apresentar o estado da produção sobre ginástica, mais especificamente sobre ginástica escolar no Brasil. Esta produção é fundamental para o desenvolvimento geral do projeto de pesquisa em questão, pois, oferece um balanço das discussões, possibilitando avançarmos cientificamente a partir das elaborações já existentes.

Com o intuito de elaborar um balanço da produção científica sobre ginástica escolar nos periódicos nacionais (Motrivivência, Movimento, Revista Brasileira de Ciências do Esporte (RBCE), Motriz, Pensar a Prática) e no banco de teses da CAPES, este artigo ainda se dispõe a discutir as contribuições dessas produções para a formação profissional, seja propondo a inclusão de conteúdos curriculares, modificar currículo, incluir novas práticas; e contribuir com o suporte teórico para a proposta curricular da ginástica das escolas públicas da Bahia a para do estudo "Ginástica: Alegria na Escola", no município de Amargosa. 


\section{PROCEDIMENTOS METODOLÓGICOS}

Para atingir esses objetivos utilizamos os métodos próprios da pesquisa social, alicerçado na base teórica do materialismo histórico dialético. Durante a investigação foram utilizados os procedimentos metodológicos próprios da pesquisa bibliográfica como: análise de documentos e revisão bibliográfica sobre a temática. Para acessar as fontes, recorremos aos bancos disponíveis na internet (sites das revistas e o banco de teses da CAPES). Como ferramentas científicas utilizamos o computador e as fichas de síntese. O plano foi organizado em três momentos:

1. Levantamento da produção - Nas revistas consultamos todas as edições existentes até 2011, que no total foram: 46 números da revista Movimento, 31 números da revista Motrivivência, 94 números da

RBCE, 26 números da revistas Pensar a Prática e 56 números da revista Motriz. A seleção dos artigos se deu a partir da leitura dos títulos que faziam alguma menção a ginástica. Numa segunda etapa, foram selecionados os artigos que tratam de ginástica escolar, os quais foram analisados. No banco de teses da CAPES, foram consultadas todas as teses e dissertações disponíveis, que abrangem o período de 1987 a 2010, para a seleção foi utilizado a palavra ginástica no item assunto com o marcador expressão exata;

2. Análise da produção recorrendo ao resumo analítico e ao esquema paradigmático, ${ }^{5}$ destacando as principais problemáticas e proposições no campo da Educação Física escolar presentes nestas produções;

3. Elaboração teórica final apresentando os dados da pesquisa e interpretação das análises realizadas.

\section{FUNDAMENTAÇÃO TEÓRICA}

A ginástica é um conhecimento em franco processo de extinção das aulas de Educação Física nas escolas, entre os motivos está à formação de professores que não contempla uma 
formação profissional que aborde as problemáticas das escolas, principalmente as públicas, as quais sofrem também com graves problemas de infraestrutura. ${ }^{6-8}$

Foram analisadas revistas com grande representatividade na Educação Física brasileira, principalmente na discussão sobre a educação física escolar. $\mathrm{Na}$ análise final das revistas foi possível identificar 51 artigos que tratam das problemáticas da ginástica, sendo 15 na Revista Brasileira de Ciências do Esporte (RBCE), dois na revista Motrivivência, oito na revista Movimento, 19 na revista Motriz e sete na revista Pensar a Prática.

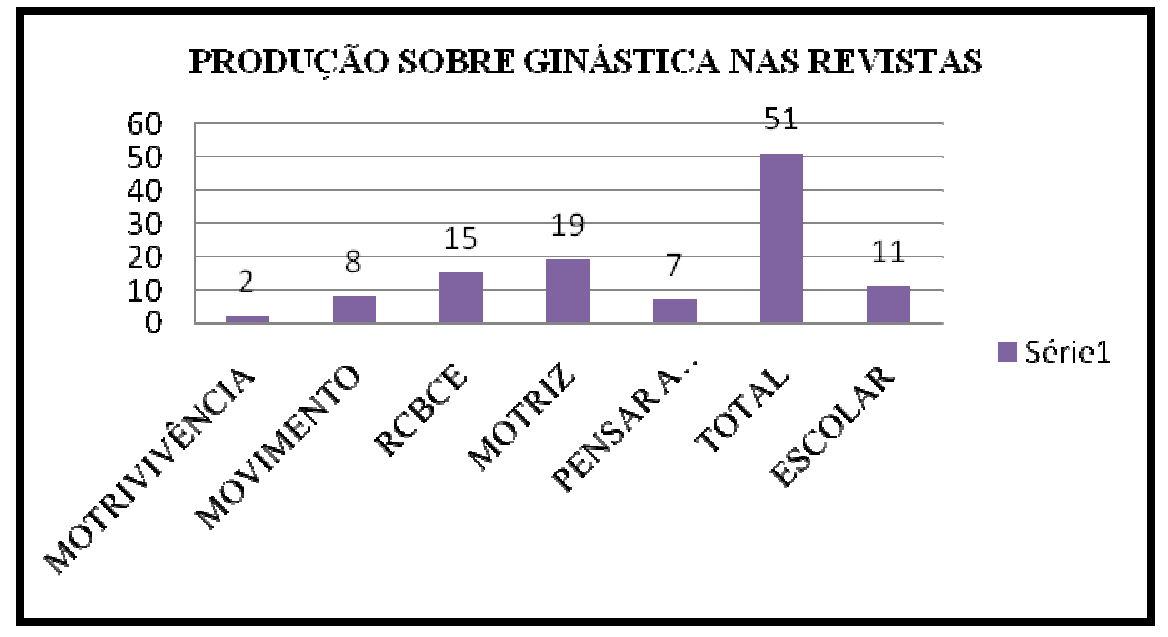

Figura 1: Produção científica sobre Ginástica nas revistas do estudo.

Entre estas produções 11 tratam da ginástica escolar, sendo este tema o terceiro mais discutido, atrás da ginástica esportiva com 16, e ginástica em academia com 24 artigos.

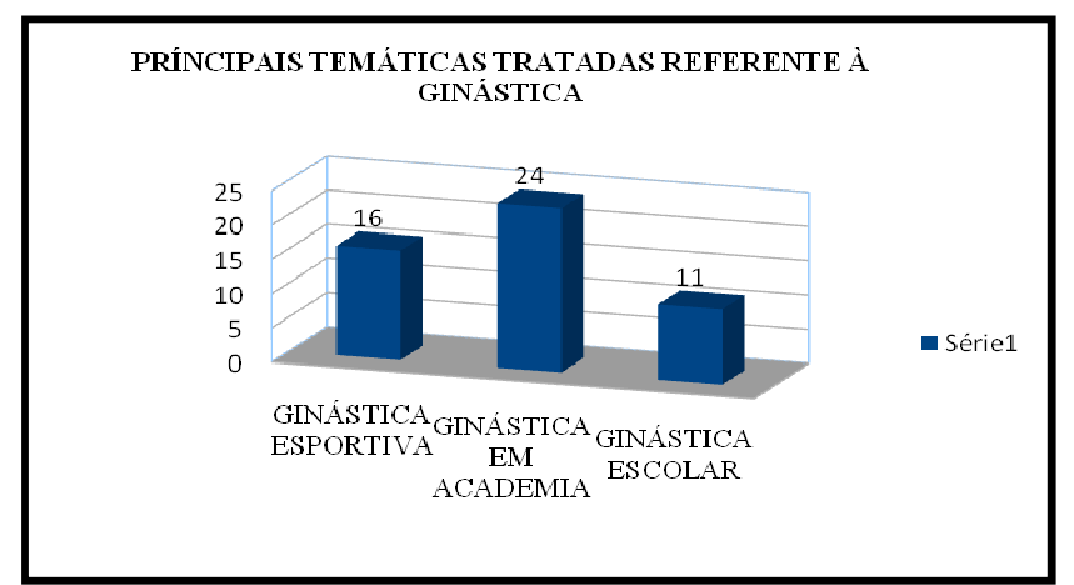

Figura 2: Principais temas referentes a Ginástica identificados nas revistas. 
No intuito de verificar a expressão da discussão sobre a ginástica nas produções científicas mais elaboradas, foram investigadas as teses e dissertações presentes no Banco de Teses da CAPES, nestas análises foram encontrados 166 trabalhos que tratam da ginástica, sendo 152 de Mestrado e 14 de Doutorado.

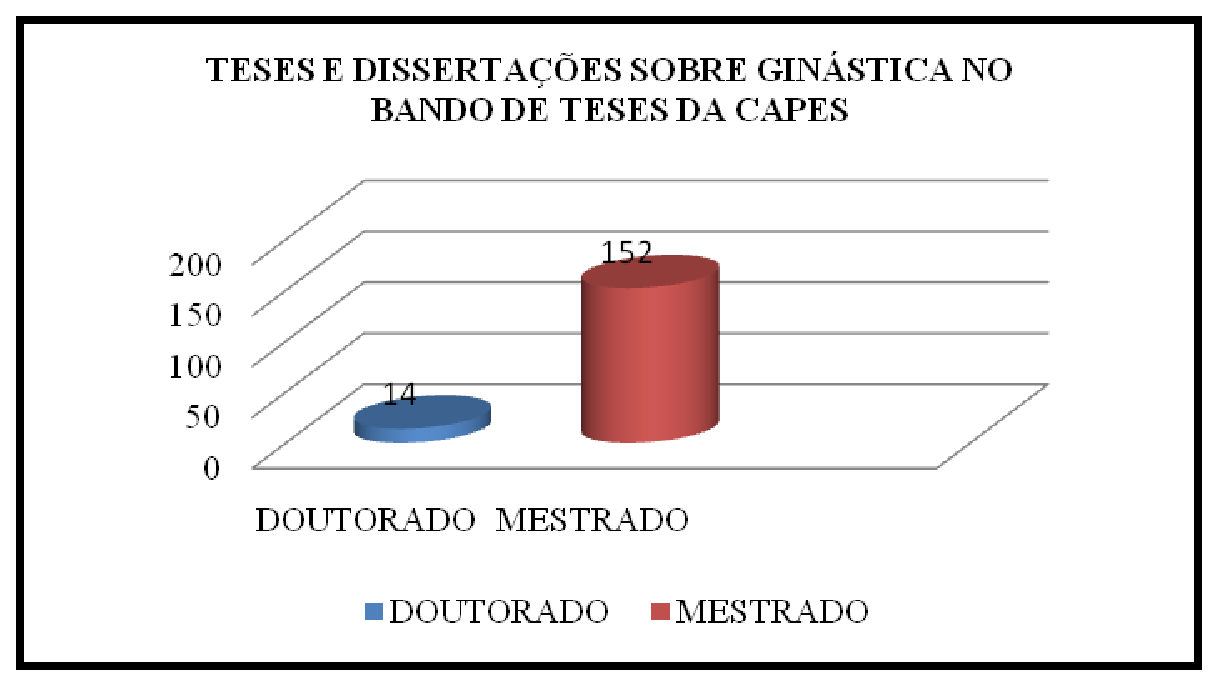

Figura 3: Teses e dissertações sobre Ginástica existente no Banco de Dados da CAPES.

Neste conjunto de trabalhos identificamos nove trabalhos que trataram da ginástica escolar, sendo 3 teses, 6 dissertações.

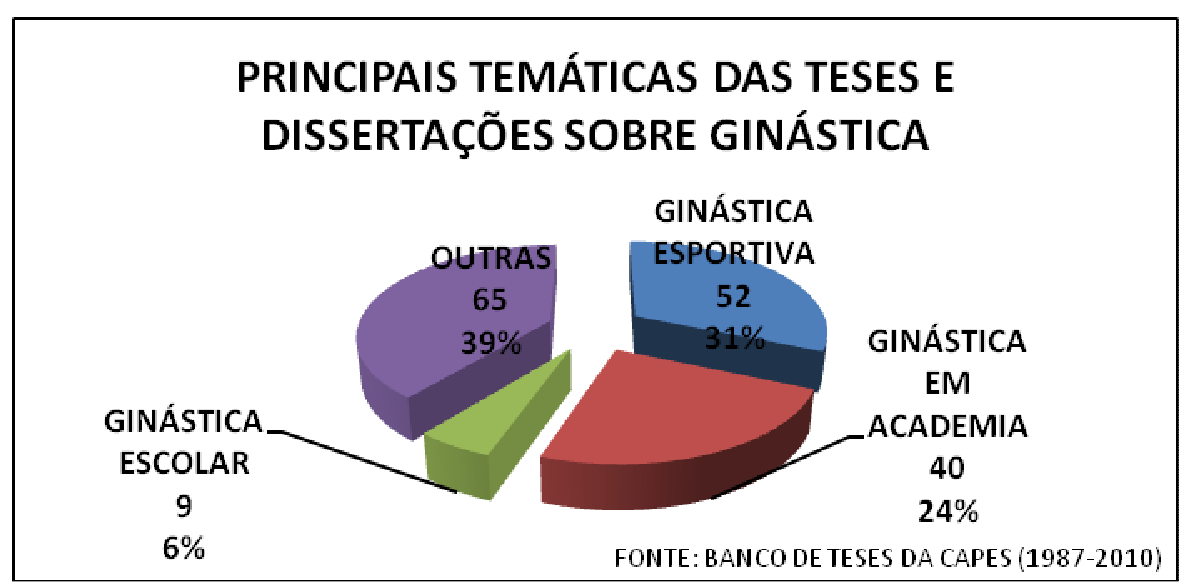

Figura 4: Principais temas das teses e dissertações sobre ginástica. 
Com uma análise ainda inicial destas produções, é possível indicar que a produção sobre ginástica escolar nas fontes pesquisadas é muito reduzida, principalmente nas teses e dissertações onde apenas $6 \%$ da produção sobre ginástica abordam a questão escolar. Essas produções também são recentes, sendo a primeira tese defendida em 1998, e primeira dissertação em 2003. A partir dos dados presentes nesta pesquisa; reconhecemos a importância de discutir a relação entre a produção científica e os fatores que dificultam o ensino da ginástica nas escolas. Diante desta constatação reconhecemos o valor de ampliar a investigação referente ao ensino da ginástica nas escolas brasileiras, suas principais problemáticas e experiências.

\section{CONSIDERAÇÕES FINAIS}

No atual momento estamos na fase de análise das produções, 11 artigos presentes nos periódicos, e nove teses e dissertação presentes no Banco de Teses da CAPES. Após a análise cuidadosa desta produção poderemos estabelecer os nexos necessários entre a produção científica e as problemáticas significativas presentes na realidade concreta da ginástica escolar brasileira.

Este artigo oferece, ainda que de forma inicial, subsídios para identificar as principais problemáticas sobre a ginástica, assim como oferece um balanço teórico da produção nacional sobre a temática contribuindo para que o projeto possa atingir os demais objetivos propostos. Esse mesmo balanço é importante para área de estudo da ginástica, pois concentra as suas principais produções em âmbito nacional, oferecendo acesso mais facilitado desta produção para os demais pesquisadores da área. A análise detalhada desta produção ainda carece de um estudo de maior abrangência, análise que consideramos fundamental na tarefa de superar as problemáticas significativas da área, tarefa que nos dispomos enfrentar no próximo período.

Indicamos que a socialização deste banco de dados sobre a ginástica escolar colabora significativamente com os estudos da área, possibilitando aos demais pesquisadores acesso fácil as principais elaborações científicas nacionais existentes, servindo de excelente ferramenta não só para essa pesquisa, mas para o ensino da ginástica, pois professores e Conexões: revista da Faculdade de Educação Física da UNICAMP, Campinas, v. 10, n. Especial, p. 1-9, dez. 2012.8 ISSN: 1983-9030 
professoras de educação física poderão se apropriar das mesmas para sua formação e elaboração de aulas.

\section{REFERÊNCIAS}

${ }^{1}$ SOARES, C. L. et al. Metodologia do ensino da Educação Física. São Paulo: Cortez, 1992.

${ }^{2}$ ORTEGA ESCOBAR, M. Conhecimento e ginástica. In: CONGRESSO DE GINÁSTICA DA BAHIA, 1., Salvador, 2003. Anais... Salvador, 2003.

${ }^{3}$ TEIXEIRA, D. R. et al. Ginástica alegria na escola. In: TAFFAREL, C. N. Z.; HILDEBRANDT-STRAMANN, R. (Org.). Currículo e Educação Física: formação de professores e prática pedagógica nas escolas. Ijuí: Ed. da Unijuí, 2007. p. 341-356.

${ }^{4}$ FREITAS, L. C. Ciclos, seriação, e avaliação: confrontos de lógicas. São Paulo: Moderna, 2003.

${ }^{5}$ SÁNCHEZ GAMBOA, S. A. Fundamentos para la investigácion educativa: presupuestos epistemológicos que orientam al investigador. Santa Fé de Bogotá: Cooperativa: Editorial Magisterio, 1998. p.144. 